\title{
Comment on "Central Demyelinating Diseases After Vaccination Against Hepatitis B Virus: A Disproportionality Analysis Within the VAERS Database"
}

\author{
Carine Cohen $^{1} \cdot$ Annick Houdeau $^{1}$ - Alena Khromava ${ }^{1}$
}

Published online: 29 September 2018

(c) The Author(s) 2018

We read with interest Mouchet and Bégaud's recent analysis of the Vaccine Adverse Events Reporting System (VAERS) database [1]. They concluded that multiple sclerosis (MS) cases were up to five times more likely to be reported after a hepatitis B (HB) vaccination than after any other vaccination, and that the origin of the cases (United States [US] or non-US) did not influence their findings, before advocating further studies into this potential link. However, we disagree with their conclusions and highlight a fundamental flaw in their analysis.

In the 1990s, a suspected link between MS and HB vaccination received significant media coverage in France, which led to distrust in HB vaccines. Several litigation cases involving vaccinated healthcare professionals received financial compensation in France [2], which impacted the reporting of MS cases after $\mathrm{HB}$ vaccines versus other vaccines. For instance, MS cases that onset within 120 days after HB vaccination were reported to the VAERS after a time lag of several years (data not shown). In the early 2000s, after reviewing the evidence, several groups of experts concluded that there was an absence of evidence to support a causal association between HB vaccine and MS [3, 4]. Thus, the perception of risk changed over time, peaking in 1990s, and was particularly acute in France. Consistent with this, the authors found (see Table 1 in their article) that the geographical distribution of MS cases reported after HB vaccination differed significantly to that of MS cases reported after other

This comment refers to the article available at https://doi. org/10.1007/s40264-018-0652-4.

An author's reply to this comment is available athttps://doi. org/10.1007/s40264-018-0734-3

Carine Cohen

carine.cohen@sanofi.com

1 Global Pharmacovigilance, Sanofi Pasteur, 14 Espace Henri Vallée, 19/23 Boulevard Jules Carteret, 69007 Lyon, France vaccines. They pooled both datasets in the main analyses and conclusions, and showed the impact of this pooling in their subgroup analysis (see Table 2 in their article). Table 1 in their article also shows an even larger heterogeneity according to the year of vaccination, with $52 \mathrm{MS}$ cases reported after HB vaccination in 2001-2017 versus 128 MS cases in 1987-2000, while after other vaccines, 124 MS reported cases were vaccinated in 2001-2017 versus 52 MS cases in previous years. We were therefore surprised that despite this significant and expected temporal pattern, the authors did not account for it. Instead, they chose to pool all data over three decades in all analyses.

We also read with interest a systematic review and metaanalysis also published by Mouchet and Bégaud earlier this year [5]. This second article identified 13 studies on the risk of central demyelination after $\mathrm{HB}$ vaccination, and concluded that there is no evidence of an association. We find it curious that neither paper refers to the other or discusses their contradictory findings. To reduce bias due to confounding, disproportionality methods require subgroup analyses, e.g. by excluding litigation cases, and subgrouping by region or period. Ignoring diversity and potential confounding factors within a dataset may result in either signals being masked, or false associations being flagged as potential signals $[6,7]$. In the VAERS, which is co-owned by the US Centers for Disease Control and Prevention (CDC) and US Food and Drug Administration (FDA), foreign adverse event reports are cases occurring abroad, and are mostly reported by vaccine manufacturers in compliance with FDA regulations. These reports are of variable data quality and completeness due to the different national reporting practices and surveillance system quality, and, consequently, US CDC analyses typically separate foreign reports from US cases [8].

We attempted to reproduce the authors' data extraction (via Empirica software, Oracle) and found discrepancies with their data in the number of other events with onset 
Table 1 Reporting ratios for multiple sclerosis per region and vaccination year considered: 1987-2000 and 2001-2017; 1987-2004 and 2005-2017

\begin{tabular}{|c|c|c|c|c|c|}
\hline Location of cases & Vaccination year & Vaccines & MS cases & Other events & ROR $(95 \% \mathrm{CI})$ \\
\hline \multirow[t]{8}{*}{ USA } & \multirow[t]{2}{*}{$1987-2000$} & $\mathrm{HB}$ & 48 & 8088 & 2.52 \\
\hline & & Other & 41 & 17,385 & $(1.66-3.82)$ \\
\hline & \multirow[t]{2}{*}{ 2001-2017 } & $\mathrm{HB}$ & 12 & 7338 & 1.86 \\
\hline & & Other & 68 & 77,290 & $(1.01-3.44)$ \\
\hline & \multirow[t]{2}{*}{ 1987-2004 } & $\mathrm{HB}$ & 55 & 9896 & 2.98 \\
\hline & & Other & 52 & 27,849 & $(2.04-4.35)$ \\
\hline & \multirow[t]{2}{*}{ 2005-2017 } & $\mathrm{HB}$ & 5 & 5530 & 1.06 \\
\hline & & Other & 57 & 66,826 & $(0.42-2.65)$ \\
\hline \multirow[t]{8}{*}{ Foreign } & \multirow[t]{2}{*}{$1987-2000$} & $\mathrm{HB}$ & 80 & 724 & 8.56 \\
\hline & & Other & 6 & 465 & $(3.71-19.79)$ \\
\hline & \multirow[t]{2}{*}{ 2001-2017 } & $\mathrm{HB}$ & 46 & 1611 & 2.58 \\
\hline & & Other & 52 & 4698 & $(1.73-3.85)$ \\
\hline & \multirow[t]{2}{*}{ 1987-2004 } & HB & 94 & 1092 & 10.03 \\
\hline & & Other & 7 & 816 & $(4.63-21.74)$ \\
\hline & \multirow[t]{2}{*}{ 2005-2017 } & $\mathrm{HB}$ & 32 & 1243 & 2.19 \\
\hline & & Other & 51 & 4347 & $(1.40-3.43)$ \\
\hline
\end{tabular}

$M S$ multiple sclerosis, $R O R$ reporting odds ratio, $C I$ confidence interval, $H B$ hepatitis B within 120 days after vaccination in 18- to 49-year-olds and in the number of MS cases. We calculated moving averages of the reporting odds ratio (ROR) by vaccination year (ROR for year $N$ calculated over the years $N-4$ to $N+4$ ), which showed that foreign reporting rates of MS cases after HB vaccination in the 1990s were particularly high, before decreasing markedly in the early 2000s to levels more comparable with those in the US (Fig. 1, Table 1). This illustrates that pooling these data was inappropriate.
In conclusion, given the consistency between their data in Table 1 and the well-known history of the scientific and media perception of the potential association of MS with HB, we believe that Mouchet and Bégaud's decision to pool such heterogenous data over such a long period of time was fundamentally flawed and their conclusions unfounded. In 2002, the Global Advisory Committee on Vaccine Safety concluded that there is no association between administration of the HB vaccine and MS, consistent with the US Institute of Medicine, and their position has not changed since $[9,10]$.
Fig. 1 Reporting ratios for multiple sclerosis per region considered: moving averages over 9-year periods of calendar time (i.e. ROR for vaccination year $N$ is calculated over the years $N-4$ to $N+4)$. $R O R$ reporting odds ratio

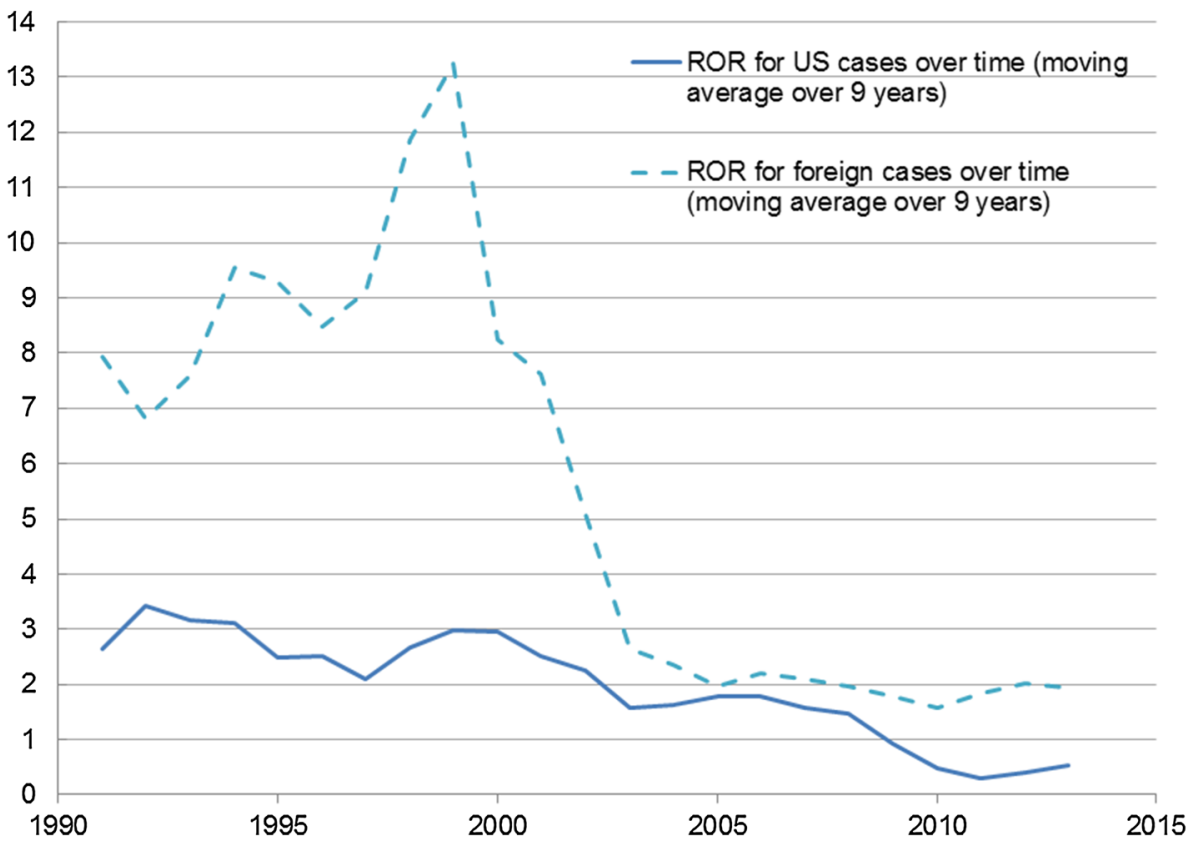


Acknowledgements The authors wish to acknowledge Aumery Billon for his assistance in checking the data, and Grenville Marsh for his editorial assistance in preparing this letter.

\section{Compliance with Ethical Standards}

Conflicts of interest Carine Cohen, Annick Houdeau and Alena Khromava are employed by Sanofi Pasteur.

Funding No sources of funding were used to assist in the preparation of this letter.

Open Access This article is distributed under the terms of the Creative Commons Attribution-NonCommercial 4.0 International License (http://creativecommons.org/licenses/by-nc/4.0/), which permits any noncommercial use, distribution, and reproduction in any medium, provided you give appropriate credit to the original author(s) and the source, provide a link to the Creative Commons license, and indicate if changes were made.

\section{References}

1. Mouchet J, Bégaud B. Central demyelinating diseases after vaccination against hepatitis B virus: a disproportionality analysis within the VAERS database. Drug Saf. 2018;41(8):767-74.

2. Rougé-Maillart CI, Guillaume N, Jousset N, Penneau M. Recognition by French courts of compensation for post-vaccination multiple sclerosis: the consequences with regard to expert practice. Med Sci Law. 2007;47(3):185-90.

3. DeStefano F, Verstraeten T, Chen RT. Hepatitis B vaccine and risk of multiple sclerosis. Expert Rev Vaccines. 2002;1(4):461-6.
4. Demicheli V, Rivetti A, Di Pietrantonj C, Clements CJ, Jefferson T. Hepatitis B vaccination and multiple sclerosis: evidence from a systematic review. J Viral Hepat. 2003;10(5):343-4.

5. Mouchet J, Salvo F, Raschi E, Poluzzi E, Cosimo Antonazzo I, De Ponti F, et al. Hepatitis B vaccination and the putative risk of central demyelinating diseases: a systematic review and metaanalysis. Vaccine. 2018;36(12):1548-55.

6. Seabroke S, Candore G, Juhlin K, Quarcoo N, Wisniewski A, Arani R, et al. Performance of stratified and subgrouped disproportionality analyses in spontaneous databases. Drug Saf. 2016;39(4):355-64.

7. European Medicines Agency. Screening for adverse reactions in EudraVigilance. EMA/849944/2016. Available at: http://www. ema.europa.eu/docs/en_GB/document_library/Other/2016/12/ WC500218606.pdf. Accessed 17 Jul 2018

8. US Centers for Disease Control and Prevention. Advisory Guide to the Interpretation of VAERS Data. Available at: https://wonde r.cdc.gov/wonder/help/vaers/VAERS\%20Advisory\%20Guide.htm. Accessed 17 Jul 2018

9. World Health Organization, WHO Global Advisory Committee on Vaccine Safety. The Global Advisory Committee on Vaccine Safety rejects association between Hepatitis B vaccination and multiple sclerosis (MS). 2002. Available at: http://www.who.int/ vaccine_safety/committee/topics/hepatitisb/ms/en/. Accessed 17 Jul 2018

10. World Health Organisation. Summary of WHO Position Paper on Hepatitis B Vaccines, July 2017. Available at: http://www.who. int/immunization/policy/position_papers/who_pp_hepb_2017_ summary.pdf. Accessed 17 Jul 2018 